\title{
Indwelling Pleural Catheter Insertion Following Inefficient Thoracoscopic Decortication in Postpneumonic Empyema: Beneficial or Contraindicated?
}

\author{
Gabor Egri, Rakesh Krishnadas, Peter Froeschle
}

Royal Devon and Exeter NHS Trust, Exeter, UK.

Email: egriga@gmail.com, rakeshkrishnadas@yahoo.com, peter.froeschle@nhs.net

Received August $26^{\text {th }}, 2013$; revised September $26^{\text {th }}, 2013$; accepted October $3^{\text {rd }}, 2013$

Copyright (C) 2013 Gabor Egri et al. This is an open access article distributed under the Creative Commons Attribution License, which permits unrestricted use, distribution, and reproduction in any medium, provided the original work is properly cited. In accordance of the Creative Commons Attribution License all Copyrights (C) 2013 are reserved for SCIRP and the owner of the intellectual property Gabor Egri et al. All Copyright (C) 2013 are guarded by low and by SCIRP as a guardian.

\begin{abstract}
Video assisted thoracic surgery in advanced stage postpneumonic empyema aims for thorough debridement and washout of the pleural space followed by an attempt to release the entrapped lung (decortication). When the latter isn't successful, and the patient is in a poor performance status, applying tube thoracostomy is the usual routine, to avoid conversion to thoracotomy and open decortication. Tube thoracostomy, however, is associated with complications necessitating further surgery, needs long term follow up and also entails quality of life distorting issues. To overcome these disadvantages, we instead inserted a Pleur $\mathrm{X}^{\circledR}$ indwelling pleural catheter in four patients in the above situation. The method brought success (lung re-expansion and complete or partial pleurodesis) without the need for further surgery or quality of life problems in either patient. Although the use of the indwelling pleural catheter in infected pleural space is not recommended by manufacturers, we noted no complications.
\end{abstract}

Keywords: Pleural Empyema; VATS; Trapped Lung; Decortication; Indwelling Pleural Catheter

\section{Introduction}

Pleural empyema formation in association with pneumonia is a progressive process and has been classified into three stages. Stage I represents a "simple" parapneumonic exudate; Stage II is a "complex" fibrino-purulent phase and Stage III is a chronic, organizing phase with scar tissue formation [1]. While Stage I empyema is well managed by antibiotics $+/-$ drainage, more advanced stages need video assisted thoracoscopic surgery (VATS) [2-4]. The aim of the thoracoscopic operation is to eliminate infection by clearing all septic fluid and debris in the pleural space. Also, all measures must be taken to free the lung from anything that restricts its re-expansion by two procedures: lysis of adhesions and decortication. The former is usually straightforward, but thoracoscopic decortication (stripping off the fibrous peel that "traps" the lung in advanced stages) can be challenging and is sometimes impossible. The general practice when efficient decortication is not feasible by VATS is conversion to thoracotomy and open decortication [5-7]. There are patients, however, who being severely compromised by co-morbidities and the sepsis itself, are too debilitated to withstand the conversion to the above open surgery. In their cases decision to perform tube-thoracostomy (partial single rib resection with permanent drain insertion) is generally taken. Tube-thoracostomy is not ideal on the long term, patients need longstanding postoperative follow up and may need further surgical input as the drain site on the chest wall can get infected and the drain can get blocked or fall out. An inefficient tube thoracostomy has to be converted by a second operation to "open window" thoracostomy, with a need for vacuum assisted closure for a lengthy period. Tube thoracostomy also exerts a considerable negative effect on quality of life (QOL). The unsightly draining system (consisting of a large-bore drain and a bag collecting septic fluid) is worn by the patients at all times. This disturbs sleep and causes a hindrance in everyday activities. In our article we report on four patients with advanced stage empyema, where during VATS, after unsuccessful decortication, we applied a new method to avoid both thoracotomy and thoracostomy. 


\section{Patients and Method of Management}

The method was applied on four patients presenting with parapneumonic, Stage II/III empyema in 2010/2011 (demographics and the characteristics of the clinical course summarized in Table 1). The general performance status of the patients was described using the Eastern Cooperative Oncology Group (ECOG) scale. We quote ECOG Grades 2 and 3 here: "Grade 2: ambulatory and capable of all selfcare but unable to carry out any work activities, up and about more than $50 \%$ of waking hours; Grade 3 : capable of only limited selfcare, confined to bed or chair more than $50 \%$ of waking hours" [8]. The American Society of Anesthesiologists' score (ASA) was also used to classify the health state of our patients. This was determined by anaesthetists at the time of operating. We quote ASA 2-4 here: "ASA2: a patient with mild systemic disease; ASA3: a patient with severe systemic disease; ASA4: a patient with severe systemic disease that is a constant threat to life" [9]. Combining the ECOG grades and ASA scores of the patients we also created three "overall appearance" categories ("Poor performer" if ECOG grade plus ASA score equalled 6 or more, "Intermediate performer", if it was 3, 4, or 5, and "Good performer" if it was 2, or less).

Patients 1 and 2 were in Poor performance status. Patient 1 was even deemed not fit for general anaesthesia and his VATS was performed under local anaesthesia with sedation. His co-morbidities amongst many others comprised of severe ischemic heart disease and end-stage renal failure. Patient 2 had decompensated, alcohol-related liver cirrhosis and concurrent diarrhoea from Norovirus infection as co-morbidities. Patient 3 and Patient 4 were not so debilitated, their co-morbidities comprised of hypertension, atrial flutter, hyperlipidaemia, bipolar disorder, tobacco and cannabis smoking. On operation, all four patients' lungs were trapped with a cortex on the visceral pleura and showed no re-expansion on 30 $\mathrm{cmH}_{2} \mathrm{O}$ airway pressure ventilation. The attempted décortication brought no success and even a small air leak was created in one of them (Patient 3). After debridement and multiple washings, an indwelling pleural catheter (IPC) $\left(\right.$ PleurX ${ }^{\circledR}$, Pleural Catheter Drainage System, Care Fusion, San Diego, USA) was inserted, along the same principles we apply when dealing with trapped lungs caused by non septic conditions (e.g. malignant effusions). A temporary $28-32 \mathrm{Fr}$ chest drain was also inserted and was connected to low $\left(10-20 \mathrm{cmH}_{2} \mathrm{O}\right)$ suction in all cases. The rationale of inserting the chest drains was to avoid early blockage of the IPC with any remnant debris. The chest drains were removed on the second or third postoperative day and the patients were discharged home with the IPCs in situ. Based on intraoperative clinical decision Patient 2 and Patient 4 were started on co-amoxiclave antibiotic. Initial results of microbiologic examinations of intraoperative samples arrived on postoperative day 2 and were negative in all patients. Patient 2's antibiotic had been stopped due to this negative preliminary microbiology result and clinical improvement, and it was not restarted when the enrichment culture eventually detected a microorganism (Micrococcus species). Patient 4, although the culture was negative, had his co-amoxiclave for two weeks. All patients were discharged from hospital in $3-6$ days from the operation. The IPCs were drained by district nurses as their usual routine in non-empyema patients (every other day initially, then drainage frequency adjusted individually, according to volume drained).

\section{Results}

Patient 1 needed readmission one week after his discharge for a bilateral pulmonary infection proven by elevated inflammatory markers and inflammatory signs on chest CT. The repeat culture of the fluid gained from the IPC at this time revealed Staphylococcus capitis (a facultative anaerob, living on the human skin). After a few days on free drainage and intravenous Co-Amoxiclav, the regular periodical drainage of the IPC was continued and the patient was discharged on oral antibiotic. On follow-up, he was seen to develop a fixed basal space with Staphylococcus capitis still present in the drain cultures. The IPC was therefore left in place for long time but at the end it was removed at 33 weeks, as there was no substantial fluid collection in the "pocket" and the patient hadn't presented with signs of sepsis, or elevation of inflammatory markers including CRP. No further attempts were made to surgically close the space due to the high risk originating from his co-morbidities. He died from his co-morbidities a year after catheter removal, no suggestion was raised of his death being related to his previous empyema or surgery. Patient 2's lung re-expansion and pleurodesis was gradually achieved with minimal callus formation and the IPC was removed in 14 weeks. Unfortunately he died a month after drain removal. His death was due to deterioration of his liver disease and pneumonia on the contralateral side and was not related to his previous empyema or surgery. Patient 3, who originally had a small air leak which temporarily healed, opened up again his air leak. A fixed basal pleural space developed without any fluid or debris in it (the IPC drained only air), therefore the IPC was removed at 10 weeks. The option of open decortication $+/-$ partial thoracoplasty to close the remnant space was offered, but the patient chose a watch \& wait policy. No recurrence of his disease has been reported to date. Patient 4's lung re-expansion and pleurodesis was achieved very quickly and the IPC was removed in 3 weeks (Figure 1). 
Beneficial or Contraindicated?

Table 1. Clinical summary of patients with pleural empyema undergoing VATS who received an IPC instead of thoracostomy or conversion to thoracotomy.

\begin{tabular}{|c|c|c|c|c|c|c|}
\hline $\begin{array}{l}\text { Patient } \\
\text { (age, gender) }\end{array}$ & $\begin{array}{l}\text { ECOG }{ }^{\mathrm{a}} \text { grade, } \mathrm{ASA}^{\mathrm{b}} \text { score } \\
\text { (“overall appearance category”) }\end{array}$ & $\begin{array}{c}\text { Type of } \\
\text { Anaesthesia }\end{array}$ & $\begin{array}{c}\text { Detected microorganism } \\
\text { in pleural space/ } \\
\text { Antibiotic applied }\end{array}$ & $\begin{array}{l}\text { Discharge } \\
\text { from hospital }\end{array}$ & $\begin{array}{l}\text { Indwelling } \\
\text { pleural Catheter } \\
\text { removal at }\end{array}$ & $\begin{array}{l}\text { The achieved } \\
\text { pleurodesis }\end{array}$ \\
\hline $\begin{array}{l}\text { No. } 1 \\
\text { (74 years, } \\
\text { male) }\end{array}$ & $\begin{array}{c}\text { ECOG3, ASA4 } \\
\text { ("Poor performer") }\end{array}$ & Local + Sedation & $\begin{array}{c}\text { Staphylococcus } \\
\text { capitis/Co-amoxiclave }\end{array}$ & Postop. day 4 & 33 weeks & $\begin{array}{l}\text { Partial pleurodesis } \\
\text { (fixed space) }\end{array}$ \\
\hline $\begin{array}{l}\text { No. } 2 \\
\text { (52 years, } \\
\text { male })\end{array}$ & $\begin{array}{c}\text { ECOG3, ASA3 } \\
\text { ("Poor performer") }\end{array}$ & General & Micrococcus species & Postop. day 4 & 14 weeks & $\begin{array}{l}\text { Complete radiologic } \\
\text { pleurodesis }\end{array}$ \\
\hline $\begin{array}{l}\text { No. } 3 \\
\text { (65 years, } \\
\text { male) }\end{array}$ & $\begin{array}{c}\text { ECOG2, ASA3 } \\
\text { ("Intermediate performer") }\end{array}$ & General & No microorganism & Postop. day 3 & 10 weeks & $\begin{array}{l}\text { Partial pleurodesis } \\
\quad \text { (fixed space) }\end{array}$ \\
\hline $\begin{array}{l}\text { No. } 4 \\
\text { (33 years, } \\
\text { male) }\end{array}$ & $\begin{array}{c}\text { ECOG2, ASA2 } \\
\text { ("Intermediate performer") }\end{array}$ & General & $\begin{array}{l}\text { No microorganism/ } \\
\text { Co-amoxiclave }\end{array}$ & Postop. day 6 & 3 weeks & $\begin{array}{l}\text { Complete radiologic } \\
\text { pleurodesis }\end{array}$ \\
\hline
\end{tabular}

${ }^{\mathrm{a}}$ ECOG: Eastern Cooperative Oncology Group; ${ }^{\mathrm{b}}$ ASA: American Society of Anaesthetists score.
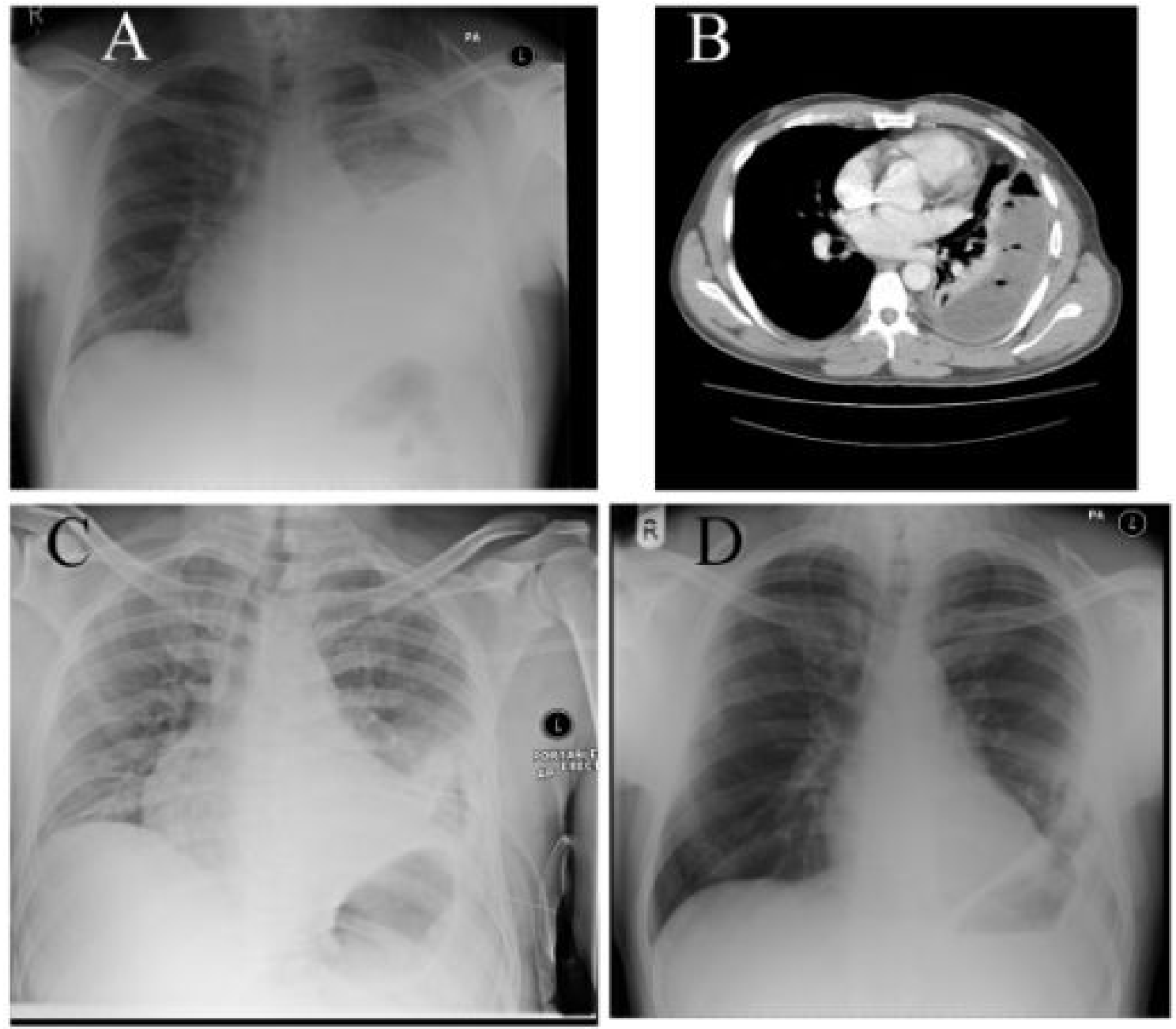

Figure 1. Patient 4. Legend: (A), (B) Preoperative chest X-ray and chest CT shows that medical drainage and treatment had been unsuccessful in this patient with loculated, Stage II/III empyema; (C) Chest X-ray taken immediately after VATS adhesiolyis, debridement, lavage and IPC insertion. Lung not expanded yet, IPC in situ; (D) Follow up Chest X-ray at 7 weeks after surgery shows reasonable pulmonary re-expansion with some pleural thickening, but no volume loss. 


\section{Discussion}

The IPC has been introduced and widely used for pleurodesis in case of trapped lung in context of malignant pleural effusion [10]. It provides re-expansion of the lung by repeated intermittent drainage with negative pressure, performed hygienically and safely by district nurses or the patients themselves. The catheter when not in use is covered by a soft waterproof dressing under the clothes and causes little disturbance in patients' everyday life. If inserted with a good technique the chances of chest wall infection and fall out are negligible. The use of IPCs in infected pleural space is labelled as a contraindication by the manufacturers. This notion may be explained by fear of a delayed cure of pleural empyema due to the intermittent nature of drainage, or blocked catheters, or by concerns regarding conveying infection to the chest wall along the subcutaneous tunnel. Accordingly, we have found only one publication on IPC use in empyema patients [11]. Their two patients had their IPC inserted as a salvage method using local anaesthesia as they were not fit for any kind of surgery under general anaesthesia. Our results suggest that the pleurodesis-promoting effect of IPCs known in the management of malignant effusions can also be used for infection-related lung entrapment in empyema surgery. We are well aware that a lot more cases are needed to gain enough information to draw reliable conclusions. Our feeling is however, that by our method we could avoid conversion to thoracotomy and open decortication or thoracostomy, therefore we could avoid the higher morbidity/mortality, longer mobilisation/discharge and postoperative complication rate these procedures entail. We experienced no catheter related problems in our small series, neither did our patients report any significant disturbances in their everyday lives. Hopefully more cases will underpin our preliminary results.

\section{REFERENCES}

[1] American Thoracic Society, Medical Section of the National Tuberculosis Association, "Management of Nontuberculous Empyema," American Review of Respiratory Disease, Vol. 85, 1962, p. 935.

[2] C. J. Wozniak, D. E. Paull, J. E. Moezzi, et al., "Choice of First Intervention Is Related to Outcomes in the Management of Empyema," The Annals of Thoracic Surgery, Vol. 87, No. 5, 2009, pp. 1525-1530. http://dx.doi.org/10.1016/j.athoracsur.2009.01.028

[3] S. P. Luh, M. C. Chou, L. S. Wang, J. Y. Chen and T. P. Tsai, "Video-Assisted Thoracoscopic Surgery in the Treatment of Complicated Parapneumonic Effusions or Empyemas," Chest, Vol. 127, No. 4, 2005, pp. 1427-1432. http://dx.doi.org/10.1378/chest.127.4.1427

[4] R. W. Light, "Parapneumonic Effusions and Empyema," Proceedings of the American Thoracic Society, Vol. 3, No. 1, 2006, pp. 75-80. http://dx.doi.org/10.1513/pats.200510-113JH

[5] B. Y. Kim, B. S. Oh, W. C. Jang, Y. I. Min, Y. K. Park and Y. C. Park, "Video-Assisted Thoracoscopic Decortication for Management of Postpneumonic Pleural Empyema," The American Journal of Surgery, Vol. 188, No. 3, 2004, pp. 321-324. http://dx.doi.org/10.1016/j.amjsurg.2004.06.009

[6] G. Melloni, A. Carretta, P. Ciriaco, et al., "Decortication for Chronic Parapneumonic Empyema: Results of a Prospective Study," World Journal of Surgery, Vol. 28, No. 5, 2004, pp. 488-493. http://dx.doi.org/10.1007/s00268-004-7213-y

[7] B. C. Tong, J. Hanna, E. M. Toloza, et al., "Outcomes of Video-Assisted Thoracoscopic Decortication," The Annals of Thoracic Surgery, Vol. 89, No. 1, 2010, pp. 220225. http://dx.doi.org/10.1016/j.athoracsur.2009.09.021

[8] M. M. Oken, R. H. Creech, D. C. Tormey, et al., "Toxicity and Response Criteria of the Eastern Cooperative Oncology Group," American Journal of Clinical Oncology, Vol. 5, No. 6, 1982, pp. 649-655. http://dx.doi.org/10.1097/00000421-198212000-00014

[9] “ASA Physical Status Classification System," American Society of Anesthesiologists, 2007. http://www.asahq.org/Home/For-Members/Clinical-Infor mation/ASA-Physical-Status-Classification-System

[10] C. A. Efthymiou, T. Masudi, J. A. C. Thorpe and K. Papagiannopoulos, "Malignant Pleural Effusion in the Presence of Trapped Lung. Five-Year Experience of PleurX Tunnelled Catheters," Interactive CardioVasc Thoracic Surgery, Vol. 9, No. 6, 2009, pp. 961-964. http://dx.doi.org/10.1510/icvts.2009.211516

[11] H. E. Davies, N. M. Rahman, R. J. Parker and R. J. O. Davies, "Use of Indwelling Pleural Catheters for Chronic Pleural Infection," Chest, Vol. 133, No. 2, 2008, pp. 546549. http://dx.doi.org/10.1378/chest.07-1742 